\title{
Efficacy and Safety of IDegAsp Versus BIAsp 30, Both Twice Daily, in Elderly Patients with Type 2 Diabetes: Post Hoc Analysis of Two Phase 3 Randomized Controlled BOOST Trials
}

Greg Fulcher · Roopa Mehta • Edmond G. Fita · Magnus Ekelund •

Stephen C. Bain

Received: August 6, 2018 / Published online: November 24, 2018

(C) The Author(s) 2018

\section{ABSTRACT}

Introduction: The majority of elderly patients ( $\geq 65$ years of age) with type 2 diabetes mellitus (T2DM) will eventually require insulin therapy, but they are particularly vulnerable to hypoglycemia and challenging to treat. Insulin degludec/insulin aspart (IDegAsp) is a novel coformulation of $70 \%$ insulin degludec and 30\% insulin aspart administered in a single injection, either once or twice daily with main meals.

Edmond G. Fita was an employee of Novo Nordisk at the time of the study.

Enhanced Digital Features To view enhanced digital features for this article go to https://doi.org/10.6084/ m9.figshare.7284923.

G. Fulcher $(\bowtie)$

Royal North Shore Hospital, University of Sydney, Sydney, NSW, Australia

e-mail: greg.fulcher@sydney.edu.au

R. Mehta

Unidad de Investigación en Enfermedades

Metabólicas, Departamento de Endocrinología y

Metabolismo, Instituto Nacional de Ciencias

Médicas y Nutrición Salvador Zubirán, Mexico City, Mexico

E. G. Fita · M. Ekelund

Novo Nordisk A/S, Søborg, Denmark

S. C. Bain

Diabetes Research Unit Cymru, Swansea University,

ABM University Health Board, Swansea, UK
Methods: A combined analysis of the phase 3 BOOST INTENSIFY PREMIX I (NCT01009580) and BOOST INTENSIFY ALL (NCT01059812) trials has previously reported lower rates of hypoglycemia during the maintenance period in patients with T2DM treated with IDegAsp twice daily (BID) versus biphasic insulin aspart 30 (BIAsp 30) BID. This post hoc analysis examined the safety and efficacy of IDegAsp versus BIAsp 30 in elderly patients from the global population of these two trials, and also from the Japanese cohort of BOOST INTENSIFY ALL.

Results: Change in $\mathrm{HbA}_{1 \mathrm{c}}$ was similar for IDegAsp versus BIAsp $30(p>0.5)$. Compared with BIAsp 30, IDegAsp resulted in significant reductions in fasting plasma glucose $(p<0.0001)$, numerically lower rates of overall and nocturnal hypoglycemia (global estimated rate ratios: $0.92[0.67 ; 1.26]_{95 \%}$ confidence interval [CI], $p=0.5980$ and $0.67[0.39 ; 1.18]_{95 \% ~ C I}$, $p=0.1676$, respectively), and a significantly lower total daily insulin dose at end of trial (global estimated treatment difference 0.79 [0.73; $0.87]_{95 \% \mathrm{CI}}, p<0.0001$ ) in elderly patients.

Conclusion: The results described here are consistent with those of the overall trial populations, demonstrating that IDegAsp BID is efficacious in elderly patients and suggesting that there is no need for special safety precautions.

Funding: Novo Nordisk.

Trial Registration: ClinicalTrials.gov identifiers, NCT01009580 and NCT01059812. 
Plain Language Summary: Plain language summary available for this article.

Keywords: Elderly; Insulin degludec/insulin aspart; Type 2 diabetes

\section{PLAIN LANGUAGE SUMMARY}

IDegAsp is a new insulin therapy for people with diabetes. It is a combination of two insulins: insulin degludec (IDeg) and insulin aspart (IAsp). Previous studies have compared the IDegAsp combination with biphasic IAsp 30 (a premixed insulin therapy related to IAsp). These studies have shown that IDegAsp improves blood glucose levels with a low risk of harmful side effects. This study examined whether IDegAsp had the same positive effect on people who are aged 65 years or older. This age group is less well represented in clinical trials compared with younger adults, so this study pooled together elderly populations from two trials. Results showed that IDegAsp also improved blood glucose levels with a low risk of harmful side effects in elderly patients, and suggests that IDegAsp can be used in elderly people with diabetes just as it is used in younger adults.

\section{INTRODUCTION}

The overall goal of type 2 diabetes mellitus (T2DM) management is to achieve good glycemic control while avoiding the adverse events (AEs) associated with diabetes progression and diabetic therapy. Additional challenges may arise when treating diabetes in elderly patients, particularly at the stage of insulin initiation $[1,2]$.

Fear of hypoglycemia is a commonly cited barrier to insulin initiation in patients of all ages $[3,4]$, but hypoglycemia is of particular concern in the elderly population (defined here as $\geq 65$ years of age). Elderly patients are more susceptible to hypoglycemia because aging is accompanied by an increased risk of impaired counter-regulatory responses to hypoglycemia [5, 6]. Hypoglycemic episodes in elderly patients have also been associated with an increased risk of fall-related events
[7] and also of dementia [8, 9] compared with patients who did not experience hypoglycemia. Consequently, achieving tight glycemic control in elderly patients while avoiding hypoglycemia is of critical importance, although frequently challenging [10].

The majority of elderly patients with a longer duration of $\mathrm{T} 2 \mathrm{DM}$ require, or will require at some point, insulin therapy to achieve glycemic control; however, insulin therapy is often underutilized in this population for the reasons described above [11]. Reducing the risk of hypoglycemia is an important focus of T2DM management and, thus, therapy design.

Long-acting (basal) and rapid-acting (bolus) insulin analogs were developed to provide a more physiological insulin action profile compared with human insulins [12]. Basal-bolus regimens can effectively control postprandial and fasting hyperglycemia; however, this involves multiple daily injections, which are another patient-perceived barrier to insulin initiation/intensification [3, 13, 14]. Although the benefit of convenience with premixed insulin compared with a basal-bolus regimen is attractive to elderly patients, traditional premixed insulin can result in an increased risk of hypoglycemia versus basal-bolus therapy [15], and-as mentioned above-this is particularly deleterious in the elderly population $[5,13,16]$.

Insulin degludec/insulin aspart (IDegAsp; Ryzodeg $^{\circledR}$, Novo Nordisk A/S, Søborg, Denmark) is the first co-formulation of these two insulins, 70\% insulin degludec (IDeg) and 30\% insulin aspart (IAsp), in a single injection, and is administered once or twice daily with main meals [17]. Importantly, the molecular properties of IDegAsp are such that the mechanism of action of each monocomponent remains unchanged and their distinct pharmacokinetic (PK)/pharmacodynamic (PD) properties are preserved in co-formulation, as well as following injection.

The basal component, IDeg, has a flat PK profile over $24 \mathrm{~h}$ and, at steady state, provides a stable, long-lasting, glucose-lowering effect, whereas the bolus component, IAsp, has a rapid onset of action and reduces glucose excursions at mealtimes [17]. Studies have shown that these PK/PD properties are preserved across special patient populations [18]. A glucose 
clamp study demonstrated that PD properties of IDegAsp, following once- or twice-daily dosing, were consistent across younger and elderly adults [19]. While previous findings have suggested that variables such as race and ethnicity may influence the pharmacological properties of rapid- and long-acting insulin analogs [20], a single-dose, euglycemic glucose clamp study demonstrated that the distinct basal and prandial components of IDegAsp that have been described in Caucasian populations are also observed in Japanese patients with type 1 diabetes mellitus (T1DM) [21]. Therefore, from a pharmacological perspective, these studies suggest that the action of IDegAsp is similar in populations of different ages and races [18].

The IDegAsp clinical trial program (BOOST) builds on that of IDeg [22-29] and demonstrates the efficacy and safety profiles of IDegAsp in the treatment of patients with T1DM and T2DM [30-32]. Global findings from the overall population of the BOOST clinical trial program suggest that IDegAsp would benefit elderly patients. For example, a combined analysis of two pivotal phase 3a trials (BOOST INTENSIFY PREMIX I [NCT01009580] and BOOST INTENSIFY ALL [NCT01059812]) has previously reported lower rates of hypoglycemia during the maintenance period in patients with T2DM treated with IDegAsp twice daily versus biphasic insulin aspart 30 (BIAsp 30) twice daily [33].

The clinical outcomes of treatment with IDegAsp compared with that of BIAsp 30 can be partly explained by their pharmacokinetic/pharmacodynamic properties. In contrast with the glucoselowering profile of IDegAsp, which consists of two distinct phases of action, the glucose-lowering effects of the soluble and protaminated fractions of BIAsp 30 overlap at approximately $6 \mathrm{~h}$ after dosing. This "shoulder effect" is partly responsible for the day-to-day variability in glycemic control observed with the intermediate-acting BIAsp 30 [18]. A rapid increase in serum concentration is observed after BIAsp 30 administration (maximum concentration reached in 2.1-2.6 h), followed by a gradual decline [34]. Appropriate timing of the second administration to ensure adequate insulin concentrations throughout the day and night and avoid episodes of hypo- or hyperglycemia is important.
This manuscript presents a post hoc pooled subanalysis of the elderly population from these two trials. In addition, a subanalysis was performed on the Japanese population of BOOST INTENSIFY ALL, because elderly Japanese patients of BOOST INTENSIFY ALL comprised the largest elderly subpopulation in these two trials $[31,32]$. In addition, the Japanese population is of special interest for investigation, as Japan has a large and growing elderly population [35], and IDegAsp use is greater in Japan than in any other country.

This post hoc analysis aimed to evaluate the safety and efficacy of IDegAsp in elderly patients with T2DM.

\section{METHODS}

\section{Trial Design}

The trial designs for BOOST INTENSIFY PREMIX I (global population) and BOOST INTENSIFY ALL (pan-Asian population) have been described previously [31, 32] and are similar (Fig. 1). Both trials were phase $3 \mathrm{a}$, randomized, parallel, openlabel, multicenter trials with an intent-to-treat design and a duration of 26 weeks.

\section{Participants}

In BOOST INTENSIFY PREMIX I, eligible patients had been treated previously with either premixed or self-mixed insulin (once or twice daily) \pm oral antidiabetic drugs (metformin, sulfonylureas, glinides, alpha-glucosidase inhibitors, dipeptidyl peptidase- 4 inhibitors, and pioglitazone) for $\geq 3$ months. In BOOST INTENSIFY ALL, patients who had been receiving once- or twice-daily basal insulin, a premixed insulin, or a self-mixed insulin \pm metformin were eligible. Inclusion criteria for the two trials were otherwise similar; patients were eligible for inclusion if they were $\geq 18$ years of age $(\geq 20$ for BOOST INTENSIFY ALL participants in Japan and Taiwan), with glycated hemoglobin $\left(\mathrm{HbA}_{1 \mathrm{c}}\right)$ $7.0-10.0 \%(53-86 \mathrm{mmol} / \mathrm{mol})$ and body mass index $(\mathrm{BMI})<40 \mathrm{~kg} / \mathrm{m}^{2}$ (BOOST INTENSIFY 
(a)

\begin{tabular}{|c|}
\hline $\begin{array}{c}\text { Patients with } \\
\text { type } 2 \text { diabetes }(n=447)\end{array}$ \\
\hline $\begin{array}{l}\text { Inclusion criteria } \\
\text { - } \text { Type } 2 \text { diabetes } \geq 6 \text { months } \\
\left.\text { - } \mathrm{HbA}_{1 \mathrm{c}} 7.0-10.0 \% \text { (53-86 } \mathrm{mmol} / \mathrm{mol}\right) \\
\text { - } \text { Previously treated with premixed insulin } \\
\text { (OD or } \mathrm{BID}) \pm \mathrm{OADs} \geq 3 \text { months } \\
\text { - } \mathrm{BMI} \leq 40 \mathrm{~kg} / \mathrm{m}^{2} \\
\text { - } \text { Age } \geq 18 \text { years }\end{array}$ \\
\hline
\end{tabular}

IDegAsp BID \pm met \pm DPP-4i \pm pio $(n=224)$

BIAsp 30 BID \pm met \pm DPP $-4 i \pm$ pio $(n=223)$

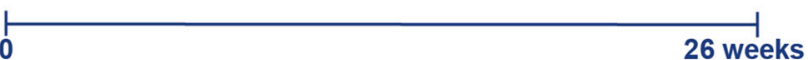

Randomized 1:1 (IDegAsp BID:BIAsp 30 BID) Open-label (b)

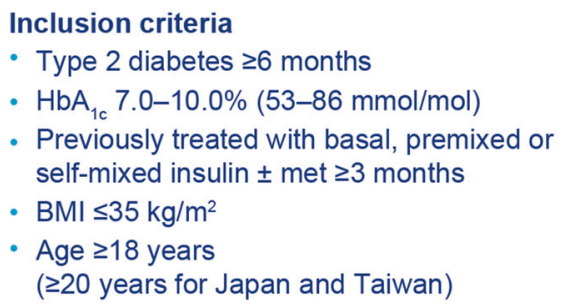

Fig. 1a-b Trial designs for a BOOST INTENSIFY PREMIX I (global patient population) [31] and b BOOST INTENSIFY ALL (pan-Asian patient population) [32]. BIAsp 30 biphasic insulin aspart 30, BID twice daily, $B M I$ body mass index, DPP-4i dipeptidyl peptidase- 4

PREMIX I) or $<35 \mathrm{~kg} / \mathrm{m}^{2}$ (BOOST INTENSIFY ALL). In both trials, patients were excluded if they had a history of recurrent severe hypoglycemia or hypoglycemic unawareness. The Japanese subgroup was drawn from the overall population. For this post hoc analysis, all patients who were aged 65 years or over were included.

\section{Compliance with Ethics Guidelines}

The protocols, protocol amendments, consent forms, and subject information sheets of the original BOOST INTENSIFY PREMIX I and BOOST INTENSIFY ALL trials were reviewed and approved by health authorities according to local regulations and by the local independent

\section{IDegAsp BID \pm met $(n=282)$}

\section{BIAsp 30 BID \pm met $(n=142)$}

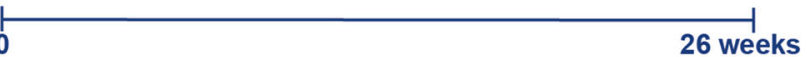

Randomized 2:1 (IDegAsp BID:BIAsp 30 BID)

Open-label

inhibitor, $H b A_{1 c}$ glycated hemoglobin, IDegAsp insulin degludec/insulin aspart, met metformin, $n$ number randomized, $O A D$ oral antidiabetic drug, $O D$ once daily, pio pioglitazone

ethics committees prior to trial initiation $[31,32]$. The trials were performed in accordance with the Declaration of Helsinki and good clinical practice [36, 37]. In summary, all procedures performed in studies involving human participants were in accordance with the ethical standards of the institutional and/or national research committee and with the 1964 Declaration of Helsinki and its later amendments or comparable ethical standards. Informed consent was obtained from all individual participants included in the study.

\section{Assessments and Statistical Analyses}

The current analyses present pooled data from both trials for the elderly subpopulation. The 
primary endpoint in both trials was change from baseline in $\mathrm{HbA}_{1 \mathrm{c}}$ after 26 weeks of treatment. A linear regression model (analysis of covariance) was used to analyze the change in $\mathrm{HbA}_{1 \mathrm{c}}$ from baseline to end of treatment with trial, treatment, sex, geographic region, and antidiabetic treatment at screening as grouping factors and age and baseline response as covariates. For individual trial groups, trial is not included as a fixed effect. Missing data were accounted for using the last observation carried forward method. Fasting plasma glucose (FPG) and insulin dose (log transformed) were analyzed using the same model.

The number of treatment-emergent confirmed hypoglycemic events was analyzed with a negative binomial regression model, using a log-link function adjusted for trial, treatment, sex, geographic region, and antidiabetic treatment at screening as fixed effects, age as covariate, and the logarithm of the exposure time as offset.

\section{Hypoglycemia Classification}

Confirmed hypoglycemia included severe episodes (episodes requiring the assistance of another person to actively administer carbohydrate, glucagon, or other resuscitative actions) and episodes confirmed by plasma glucose $(\mathrm{PG} ;<56 \mathrm{mg} / \mathrm{dL}[3.1 \mathrm{mmol} / \mathrm{L}])$ or full blood glucose $(<50 \mathrm{mg} / \mathrm{dL} \quad[2.8 \mathrm{mmol} / \mathrm{L}])$ measurements that were handled by the patient himself/herself, and could be with or without symptoms consistent with hypoglycemia. Nocturnal hypoglycemia was defined as episodes of confirmed hypoglycemia that occurred between 00:01 and 05:59 $\mathrm{h}$ (inclusive).

\section{Safety}

All patients receiving at least one dose of trial product were included in the safety analysis set. Safety was assessed using overall confirmed hypoglycemia and nocturnal hypoglycemia, based on the Novo Nordisk classification for hypoglycemia (plasma glucose $56 \mathrm{mg} / \mathrm{dL}$ $[<3.1 \mathrm{mmol} / \mathrm{L}])$. Adverse events were coded using the most recent version of Medical Dictionary for Regulatory Activities (MedDRA) coding (version 13.0 for BOOST INTENSIFY PREMIX I and version 13.1 for BOOST INTENSIFY ALL).

\section{RESULTS}

\section{Baseline Characteristics}

The combined analysis comprised 271 patients (representing $31.2 \%$ of the total population from the two trials), of whom 146 were treated with IDegAsp twice daily and 125 were treated with BIAsp 30 twice daily. Japanese patients comprised the largest subgroup $(N=72,26.6 \%$ of the analyzed cohort). Baseline characteristics for the subpopulation of patients aged $\geq$ 65 years from each trial and from the pooled data are shown in Table 1 . The mean age at baseline, BMI, duration of diabetes, $\mathrm{HbA}_{1 \mathrm{c}}$ (\%; $\mathrm{mmol} / \mathrm{mol}$ ), and FPG were similar for both treatment arms in the pooled data. BMI at baseline was lower in the pan-Asian population compared with the global population. Duration of diabetes was longer in the pan-Asian population compared with the global population.

\section{Glycemic Control}

There were no statistically significant differences in $\mathrm{HbA}_{1 \mathrm{c}}$ in the combined analysis between treatment with IDegAsp or BIAsp 30 (estimated treatment different [ETD, IDegAsp-BIAsp 30]: $\left.-0.02 \%[-0.19 ; 0.15]_{95 \% \mathrm{CI}}, p=0.8455\right)$. A significant reduction in FPG was observed with IDegAsp versus BIAsp 30 (ETD [IDegAsp-BIAsp 30]: $-1.41 \mathrm{mmol} / \mathrm{L}[-1.85 ;-0.96]_{95 \%}$ CI, $p<0.0001)$. Similar results were observed in Japanese patients, with an ETD (IDegAsp-BIAsp $30)$ of $-0.01 \%[-0.31 ; 0.29]_{95 \% \mathrm{CI}}, p=0.9521$ for $\mathrm{HbA}_{1 \mathrm{c}}$ and $-1.86 \mathrm{mmol} / \mathrm{L} \quad[-2.75$; $-0.97]_{95 \% \mathrm{CI}}, p<0.0001$ for FPG (Table 2 ).

\section{Hypoglycemia}

Overall confirmed and nocturnal hypoglycemic events by classification are shown, by trial population and for the combined analysis, in 
Table 1 Demographics and baseline characteristics of elderly patients ( $\geq 65$ years of age) with type 2 diabetes mellitus included in the analysis

\begin{tabular}{|c|c|c|c|c|c|c|}
\hline \multirow[t]{2}{*}{ Characteristic } & \multicolumn{2}{|c|}{$\begin{array}{l}\text { BOOST INTENSIFY } \\
\text { PREMIX I (global patient } \\
\text { population) }\end{array}$} & \multicolumn{2}{|c|}{$\begin{array}{l}\text { BOOST INTENSIFY ALL } \\
\text { (pan-Asian patient } \\
\text { population) }\end{array}$} & \multicolumn{2}{|c|}{$\begin{array}{l}\text { Total included in combined } \\
\text { analysis }\end{array}$} \\
\hline & $\begin{array}{l}\text { IDegAsp } \\
\text { BID }\end{array}$ & $\begin{array}{l}\text { BIAsp } 30 \\
\text { BID }\end{array}$ & $\begin{array}{l}\text { IDegAsp } \\
\text { BID }\end{array}$ & $\begin{array}{l}\text { BIAsp } 30 \\
\text { BID }\end{array}$ & $\begin{array}{l}\text { IDegAsp } \\
\text { BID }\end{array}$ & $\begin{array}{l}\text { BIAsp } 30 \\
\text { BID }\end{array}$ \\
\hline Full analysis set, $n$ & 66 & 70 & 80 & 55 & 146 & 125 \\
\hline Males, \% & 62.1 & 47.1 & 50.0 & 52.7 & 55.5 & 49.6 \\
\hline Age, years & $70.0(4.4)$ & $69.5(3.5)$ & $70.9(4.3)$ & $70.2(4.5)$ & $70.5(4.3)$ & $69.8(4.0)$ \\
\hline BMI, $\mathrm{kg} / \mathrm{m}^{2}$ & $30.0(4.5)$ & $29.9(4.8)$ & $24.6(2.8)$ & $24.6(3.5)$ & $27.1(4.5)$ & $27.6(5.0)$ \\
\hline $\begin{array}{l}\text { Duration of diabetes, } \\
\text { years }\end{array}$ & $15.8(7.5)$ & $17.0(8.3)$ & $20.7(8.1)$ & $19.2(8.8)$ & $18.5(8.2)$ & $18.0(8.6)$ \\
\hline $\mathrm{HbA}_{1 c}, \%$ & $8.0(0.7)$ & $8.1(0.8)$ & $8.4(0.8)$ & $8.3(0.9)$ & $8.2(0.8)$ & $8.2(0.8)$ \\
\hline $\mathrm{HbA}_{1 \mathrm{c}}, \mathrm{mmol} / \mathrm{mol}$ & $64.1(7.9)$ & $65.2(8.7)$ & $68.1(8.3)$ & $67.7(9.4)$ & $66.3(8.3)$ & $66.3(9.1)$ \\
\hline $\mathrm{FPG}, \mathrm{mg} / \mathrm{dL}$ & $156.3(42.0)$ & $151.1(36.2)$ & $142.6(44.9)$ & $146.4(51.7)$ & $148.8(44.0)$ & $149.0(43.6)$ \\
\hline $\mathrm{FPG}, \mathrm{mmol} / \mathrm{L}$ & $8.7(2.3)$ & $8.4(2.0)$ & $7.9(2.5)$ & $8.1(2.9)$ & $8.3(2.4)$ & $8.3(2.4)$ \\
\hline
\end{tabular}

Data are mean $(\mathrm{SD})$ unless otherwise stated

$B I A s p 30$ biphasic insulin aspart 30, BID twice daily, BMI body mass index, $F P G$ fasting plasma glucose, $H b A_{I c}$ glycated hemoglobin, IDegAsp insulin degludec/insulin aspart, $n$ number of patients, $S D$ standard deviation

Table 3. The estimated rate ratios for overall confirmed and nocturnal confirmed hypoglycemia for the combined analysis are shown in Fig. 2. In the combined analysis, there were fewer overall confirmed hypoglycemic events with IDegAsp (1041.18 events/100 patient-years of exposure [PYE]) compared with BIAsp 30 (1134.40 events/100 PYE), estimated rate ratio (ERR): $0.92[0.67 ; 1.26]_{95 \% \text { CI }}, p=0.5980$. There were fewer nocturnal hypoglycemic events in patients treated with IDegAsp compared with patients treated with BIAsp 30, ERR (IDegAsp/ BIAsp 30): $0.67[0.39 ; 1.18]_{95 \% \mathrm{CI}}, p=0.1676$. In the Japanese patient population, there was a $12 \%$ lower rate of overall confirmed hypoglycemia with IDegAsp compared with BIAsp 30, ERR: $0.88[0.47 ; 1.66]_{95 \% \text { сI } ; ~} p=0.7026$. There was also a $42 \%$ lower rate of nocturnal hypoglycemia with IDegAsp compared with BIAsp 30, which was not significant, ERR: 0.58 $[0.22 ; 1.51]_{95 \% \text { CI }} p=0.2643$, in the Japanese subpopulation.

\section{Insulin Dose}

Mean insulin dose at the end of the trial was significantly lower for patients treated with IDegAsp than for patients treated with BIAsp 30, with an estimated treatment ratio (ETR) of 0.79 $[0.73 ; 0.87]_{95 \%}$ CI $p<0.0001$. Results were similar and also significant in Japanese patients, with an ETR of $0.78 \quad[0.65 ; 0.95]_{95 \%} \quad$ CI, $p=0.0121$ (Table 2).

\section{Safety}

Overall, 271 patients were included in the safety analysis set, 146 of whom were in the IDegAsp treatment arm and 125 were in the BIAsp 30 treatment arm. A slightly higher percentage of patients reported one or more AE with IDegAsp versus BIAsp 30 (70.5\% vs. $60.8 \%$, respectively). There were more withdrawals among patients treated with BIAsp 30 (19.0\%) than with IDegAsp (14.4\%), but the majority of the 
Table 2 Overview of results for the elderly Japanese subpopulation of BOOST INTENSIFY ALL

\begin{tabular}{|c|c|c|c|c|c|}
\hline Characteristic & $n$ & IDegAsp BID & $n$ & BIAsp 30 BID & IDegAsp-BIAsp 30 \\
\hline \multicolumn{6}{|c|}{$\mathrm{HbA}_{1 \mathrm{c}},(\mathrm{mmol} / \mathrm{mol})$} \\
\hline Baseline & 44 & $67.0(6.5)$ & 28 & $67.8(8.6)$ & ETD: $-0.10[-3.38 ; 3.18]_{95 \% \mathrm{CI}}, p=0.9521$ \\
\hline End of trial & 44 & $53.2(7.2)$ & 28 & $53.5(7.9)$ & \\
\hline \multicolumn{6}{|l|}{$\mathrm{HbA}_{1 \mathrm{c}},(\%)$} \\
\hline Baseline & 44 & $8.3(0.6)$ & 28 & $8.4(0.8)$ & ETD: $-0.01[-0.31 ; 0.29]_{95 \% \mathrm{CI}}, p=0.9521$ \\
\hline End of trial & 44 & $7.0(0.7)$ & 28 & $7.0(0.7)$ & \\
\hline \multicolumn{6}{|l|}{ FPG, $(\mathrm{mg} / \mathrm{dL})$} \\
\hline Baseline & 44 & $147.2(40.6)$ & 28 & $151.7(46.0)$ & ETD: $-33.58[-49.63 ;-17.53]_{95 \% \mathrm{CI}}, p<0.0001$ \\
\hline End of trial & 44 & $92.5(26.8)$ & 28 & $125.9(40.3)$ & \\
\hline \multicolumn{6}{|l|}{ FPG, (mmol/L) } \\
\hline Baseline & 44 & $8.2(2.3)$ & 28 & $8.4(2.6)$ & ETD: $-1.86[-2.75 ;-0.97]_{95 \% \mathrm{CI}}, p<0.0001$ \\
\hline End of trial & 44 & $5.1(1.5)$ & 28 & $7.0(2.2)$ & \\
\hline \multicolumn{6}{|c|}{ Insulin dose $(\mathrm{U})$} \\
\hline Baseline & 43 & $27.0(13.8)$ & 28 & $22.8(11.8)$ & ETR: $0.78[0.65 ; 0.95]_{95 \% \mathrm{CI}}, p=0.0121$ \\
\hline End of trial & 43 & $34.9(20.3)$ & 28 & $39.3(21.7)$ & \\
\hline
\end{tabular}

BIAsp 30 biphasic insulin aspart 30, BID twice daily, $C I$ confidence interval, ETD estimated treatment difference, ETR estimated treatment ratio, $F P G$ fasting plasma glucose, $H b A_{1 c}$ glycated hemoglobin, IDegAsp insulin degludec/insulin aspart, $n$ number of patients

withdrawals were not a result of AEs (Table 4). The majority of the AEs were considered unlikely to be related to trial production in BOOST INTENSIFY PREMIX I (71\% with IDegAsp and 57\% with BIAsp 30) and BOOST INTENSIFY ALL (69\% with IDegAsp and 58\% with BIAsp 30).

\section{DISCUSSION}

This post hoc analysis of a pooled population of elderly patients demonstrates that treatment with IDegAsp provides effective glycemic control consistent with the effects of BIAsp 30. No statistically significant differences were seen between the two therapies in $\mathrm{HbA}_{1 \mathrm{c}}$ and in overall confirmed or nocturnal hypoglycemic events. Similar findings were observed in the subanalysis of Japanese patients. Our results are largely in agreement with those reported for the overall trial population [33], although the lower rates of hypoglycemia reported for IDegAsp vs. BIAsp 30 in the elderly population did not reach statistical significance. However, mean insulin dose at the end of the trial was significantly lower for elderly patients treated with IDegAsp compared with BIAsp 30 . The safety profile was similar for each treatment.

Hypoglycemia is a major barrier to achieving glycemic control for anyone with diabetes, but definitions of hypoglycemia vary between studies, and this can have a major effect on the reported incidence [38]. Furthermore, the outcomes and experience associated with biochemically similar hypoglycemic events can vary for different patients. Therefore, this analysis assessed the incidence of hypoglycemia with IDegAsp when applying the PG threshold of $<56 \mathrm{mg} / \mathrm{dL}$ ( $3.1 \mathrm{mmol} / \mathrm{L})$, which is similar to the threshold that the 2017 Joint Position Statement of the American Diabetes Association and the European Association for the Study of 
Table 3 Overall confirmed and nocturnal confirmed hypoglycemic episodes for elderly patients ( $\geq 65$ years of age) with type 2 diabetes mellitus

\begin{tabular}{|c|c|c|c|c|c|c|}
\hline & \multicolumn{6}{|c|}{ BOOST INTENSIFY PREMIX I (global patient population) } \\
\hline & \multicolumn{3}{|c|}{ IDegAsp BID } & \multicolumn{3}{|c|}{ BIAsp 30 BID } \\
\hline & $n(\%)$ & $\boldsymbol{E}$ & $R$ & $n(\%)$ & $E$ & $R$ \\
\hline Confirmed & $50(75.8)$ & 332 & 1093.64 & $52(74.3)$ & 407 & 1367.34 \\
\hline \multirow[t]{4}{*}{ Nocturnal confirmed } & $16(24.2)$ & 20 & 65.88 & $25(35.7)$ & 53 & 178.06 \\
\hline & \multicolumn{6}{|c|}{ BOOST INTENSIFY ALL (pan-Asian patient population) } \\
\hline & \multicolumn{3}{|c|}{ IDegAsp BID } & \multicolumn{3}{|c|}{ BIAsp 30 BID } \\
\hline & $\overline{n(\%)}$ & $E$ & $R$ & $n(\%)$ & $E$ & $R$ \\
\hline Confirmed & $62(77.5)$ & 418 & 1156.10 & $40(72.7)$ & 253 & 1031.69 \\
\hline Nocturnal confirmed & $19(23.8)$ & 58 & 160.42 & $19(34.5)$ & 37 & 150.88 \\
\hline
\end{tabular}

\begin{tabular}{|c|c|c|c|c|c|c|}
\hline & \multicolumn{6}{|c|}{ BOOST INTENSIFY ALL (Japanese subpopulation) } \\
\hline & \multicolumn{3}{|c|}{ IDegAsp BID } & \multicolumn{3}{|c|}{ BIAsp 30 BID } \\
\hline & $\overline{n(\%)}$ & 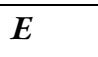 & $R$ & $\overline{n(\%)}$ & $\bar{E}$ & $R$ \\
\hline Confirmed & $31(70.5)$ & 249 & 1246.54 & $22(78.6)$ & 187 & 1441.57 \\
\hline \multirow[t]{4}{*}{ Nocturnal confirmed } & $11(25.0)$ & 30 & 150.19 & $12(42.9)$ & 29 & 223.56 \\
\hline & \multicolumn{6}{|c|}{ POOLED ANALYSIS (global patient population) } \\
\hline & \multicolumn{3}{|c|}{ IDegAsp BID } & \multicolumn{3}{|c|}{ BIAsp 30 BID } \\
\hline & $\overline{n(\%)}$ & $E$ & $R$ & $\overline{n(\%)}$ & $E$ & $R$ \\
\hline Confirmed & $112(76.7)$ & 750 & 1127.59 & $92(73.6)$ & 660 & 1215.72 \\
\hline Nocturnal confirmed & $35(24.0)$ & 78 & 117.27 & $44(35.2)$ & 90 & 165.78 \\
\hline
\end{tabular}

Confirmed hypoglycemia: patient unable to treat himself/herself and/or has a recorded plasma glucose $<56 \mathrm{mg} / \mathrm{dL}$ $(3.1 \mathrm{mmol} / \mathrm{L})$

BIAsp 30 biphasic insulin aspart 30, BID twice daily, $E$ number of events, IDegAsp insulin degludec/insulin aspart, $n$ number of patients, $R$ event rate per 100 patient-years of exposure

Diabetes recommends that all studies should report, as it is considered to be clinically significant and associated with an unequivocal hypoglycemic episode [39]. The findings presented here show that IDegAsp results in a lower rate of hypoglycemia compared with BIAsp 30 when using this threshold in the elderly subpopulation. As hypoglycemia is of particular concern in the elderly, the results of this post hoc analysis are reassuring.

An important limitation of this analysis was the relatively low number of elderly patients, and the low number of hypoglycemic episodes,

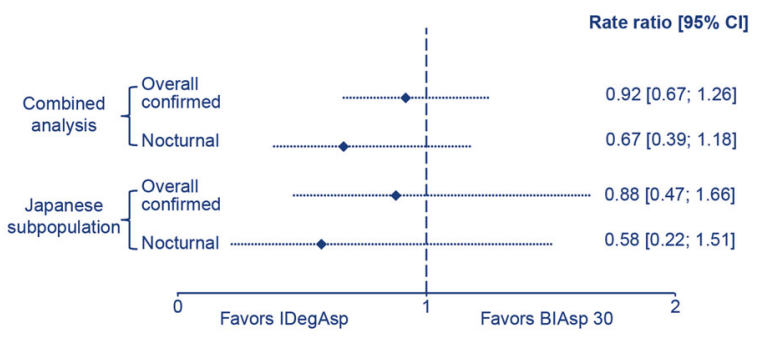

Fig. 2 Estimated rate ratios for overall confirmed and nocturnal confirmed hypoglycemia. BIAsp 30 biphasic insulin aspart 30,CI confidence interval, IDegAsp insulin degludec/insulin aspart 
Table 4 Withdrawals of elderly patients ( $\geq 65$ years of age) with type 2 diabetes mellitus participating in BOOST INTENSIFY PREMIX I and BOOST INTENSIFY ALL

\begin{tabular}{|c|c|c|c|c|c|c|}
\hline & \multicolumn{2}{|c|}{ IDegAsp BID } & \multicolumn{2}{|c|}{ BIAsp 30 BID } & \multicolumn{2}{|l|}{ Total } \\
\hline & $\begin{array}{l}\text { Number of } \\
\text { withdrawals } \\
n(\%)\end{array}$ & $\begin{array}{l}\text { Withdrawn } \\
\text { due to AE } \\
n(\%)\end{array}$ & $\begin{array}{l}\text { Number of } \\
\text { withdrawals } \\
n(\%)\end{array}$ & $\begin{array}{l}\text { Withdrawn } \\
\text { due to } \mathrm{AE} \\
n(\%)\end{array}$ & $\begin{array}{l}\text { Number of } \\
\text { withdrawals } \\
n(\%)\end{array}$ & $\begin{array}{l}\text { Withdrawn } \\
\text { due to } \mathrm{AE} \\
n(\%)\end{array}$ \\
\hline $\begin{array}{l}\text { BOOST } \\
\text { INTENSIFY } \\
\text { PREMIX I }\end{array}$ & $8(12.1)$ & $2(25.0)$ & $16(22.5)$ & $2(12.5)$ & $24(17.5)$ & $4(16.7)$ \\
\hline $\begin{array}{l}\text { BOOST } \\
\text { INTENSIFY ALL }\end{array}$ & $13(16.3)$ & $6(46.2)$ & $8(14.5)$ & $3(37.5)$ & $21(15.6)$ & $9(42.9)$ \\
\hline Overall & $21(14.4)$ & $8(38.1)$ & $24(19.0)$ & $5(20.8)$ & $45(16.5)$ & $13(28.9)$ \\
\hline
\end{tabular}

$A E$ adverse event, BIAsp 30 biphasic insulin aspart 30, BID twice daily, IDegAsp insulin degludec/insulin aspart, $n$ number of patients withdrawn at or after randomization

which prohibited statistical analysis of the incidence of severe hypoglycemia. Nonetheless, our findings show that IDegAsp results in a numerically lower rate of hypoglycemia compared with BIAsp 30, and that there were no additional safety signals in this population that might require further investigation.

\section{CONCLUSION}

In conclusion, the analytical results for elderly patients with T2D included in the phase 3 BOOST INTENSIFY PREMIX I and BOOST INTENSIFY ALL studies are consistent with those for the overall trial populations, and the low rates of hypoglycemia are reassuring, suggesting that there is no need for special precautions when using IDegAsp twice daily in elderly patients-it should be administered in a similar manner to how it is administered in younger adults.

\section{ACKNOWLEDGEMENTS}

The authors would like to thank the investigators, trial staff, and participants in the original trials for their participation. The authors also thank Mads Peter Hemmingsen, Kadriye
Kaplan, and Kenichiro Shimizu (Novo Nordisk) for their review and input to the manuscript.

Funding. Sponsorship for this study and the original BOOST INTENSIFY ALL and BOOST INTENSIFY PREMIX I trials were funded by Novo Nordisk. Novo Nordisk also funded the article processing fee. All authors had full access to all the data in the study and take responsibility for the integrity of the data and the accuracy of the data analysis.

Medical Writing and Editorial Assistance. Medical writing, editing, and submission support were provided by Aneela Majid, Victoria Atess, and Catherine Jones of Watermeadow Medical, an Ashfield company, part of UDG Healthcare plc. This support was funded by Novo Nordisk.

Authorship. All named authors meet the International Committee of Medical Journal Editors (ICJME) criteria for authorship of this article, take responsibility for the integrity of the work as a whole, and have given their approval for this version to be published.

Authorship Contributions. Greg Fulcher, Roopa Mehta, and Stephen C. Bain contributed to the analysis and manuscript writing for this study. 
Edmond G. Fita and Magnus Ekelund contributed to the design, conduct/data collection, analysis, and manuscript writing for this study.

Disclosures. Greg Fulcher has received honoraria from Novo Nordisk, MSD, Boehringer Ingelheim, AstraZeneca, and Janssen, and research support from Novo Nordisk. Roopa Mehta has received speaker/advisory board honoraria from AstraZeneca, Novo Nordisk, Amgen, Abbot, Boehringer Ingelheim, MSD, Jansen, Novartis, and Stendahl. Edmond G. Fita was an employee of Novo Nordisk at the time of the study. Magnus Ekelund is an employee of Novo Nordisk. Stephen C. Bain has received grants and personal fees from Sanofi, Eli Lilly, Boehringer Ingelheim, AstraZeneca, Novo Nordisk, and MSD.

Compliance with Ethics Guidelines. The protocol, protocol amendments, consent form, and subject information sheet of the original BOOST INTENSIFY PREMIX I and BOOST INTENSIFY ALL trials were reviewed and approved by health authorities according to local regulations, and by the local independent ethics committees prior to trial initiation $[31,32]$. The trials were performed in accordance with the Declaration of Helsinki and good clinical practice [36, 37]. In summary, all procedures performed in studies involving human participants were in accordance with the ethical standards of the institutional and/or national research committee and with the 1964 Helsinki Declaration and its later amendments or comparable ethical standards. Informed consent was obtained from all individual participants included in the study.

Data Availability. The datasets generated during and/or analyzed during the current study are available from the corresponding author on reasonable request.

Open Access. This article is distributed under the terms of the Creative Commons Attribution-NonCommercial 4.0 International License (http://creativecommons.org/licenses/ by-nc/4.0/), which permits any noncommercial use, distribution, and reproduction in any medium, provided you give appropriate credit to the original author(s) and the source, provide a link to the Creative Commons license, and indicate if changes were made.

\section{REFERENCES}

1. Singh I, Marshall MC Jr. Diabetes mellitus in the elderly. Endocrinol Metab Clin N Am. 1995;24:255-72.

2. Rosenstock J. Management of type 2 diabetes mellitus in the elderly: special considerations. Drugs Aging. 2001;18:31-44.

3. Khunti K, Millar-Jones D. Clinical inertia to insulin initiation and intensification in the UK: a focused literature review. Prim Care Diabetes. 2017;11:3-12.

4. Nakar S, Yitzhaki G, Rosenberg R, Vinker S. Transition to insulin in type 2 diabetes: family physicians' misconception of patients' fears contributes to existing barriers. J Diabetes Complic. 2007;21:220-6.

5. Abdelhafiz AH, Rodríguez-Mañas L, Morley JE, Sinclair AJ. Hypoglycemia in older people-a less well recognized risk factor for frailty. Aging Dis. 2015;6:156-67.

6. Wallace JI. Management of diabetes in the elderly. Clin Diabetes. 1999;17:1-12.

7. Kachroo S, Kawabata H, Colilla S, et al. Association between hypoglycemia and fall-related events in type 2 diabetes mellitus: analysis of a U.S. commercial database. J Manag Care Spec Pharm. 2015;21:243-53.

8. Lin $\mathrm{CH}$, Sheu WH. Hypoglycaemic episodes and risk of dementia in diabetes mellitus: 7-year follow-up study. J Intern Med. 2013;273:102-10.

9. Whitmer RA, Karter AJ, Yaffe K, Quesenberry CP Jr, Selby JV. Hypoglycemic episodes and risk of dementia in older patients with type 2 diabetes mellitus. JAMA. 2009;301:1565-72.

10. Brown AF, Mangione CM, Saliba D, Sarkisian CA. Guidelines for improving the care of the older person with diabetes mellitus. J Am Geriatr Soc. 2003;51(5 suppl guidelines):S265-80.

11. Tanwani LK. Insulin therapy in the elderly patient with diabetes. Am J Geriatr Pharmacother. 2011;9:24-36.

12. Tibaldi JM. Evolution of insulin development: focus on key parameters. Adv Ther. 2012;29:590-619. 
13. American Diabetes Association. Standards of medical care in diabetes 2017. Diabetes Care. 2017;40 (Suppl 1):S1-S135. http://care.diabetesjournals.org/ content/diacare/suppl/2016/12/15/40.Supplement_ 1.DC1/DC_40_S1_final.pdf. Accessed Oct 2018.

14. Inzucchi SE, Bergenstal RM, Buse JB, et al. Management of hyperglycemia in type 2 diabetes, 2015: a patient-centered approach: update to a position statement of the American Diabetes Association and the European Association for the Study of Diabetes. Diabetes Care. 2015;38:140-9.

15. Bellido V, Suarez L, Rodriguez MG, et al. Comparison of basal-bolus and premixed insulin regimens in hospitalized patients with type 2 diabetes. Diabetes Care. 2015;38:2211-6.

16. Nelson JM, Dufraux K, Cook PF. The relationship between glycemic control and falls in older adults. J Am Geriatr Soc. 2007;55:2041-4.

17. Heise T, Nosek L, Roepstorff C, Chenji S, Klein O, Haahr H. Distinct prandial and basal glucose-lowering effects of insulin degludec/insulin aspart (IDegAsp) at steady state in subjects with type 1 diabetes mellitus. Diabetes Ther. 2014;5:255-65.

18. Haahr H, Fita EG, Heise T. A review of insulin degludec/insulin aspart: pharmacokinetic and pharmacodynamic properties and their implications in clinical use. Clin Pharmacokinet. 2017;56:339-54.

19. Brunner M, Pieber T, Korsatko S, Kojzar H, Svendsen $\mathrm{AL}, \mathrm{Haahr} \mathrm{H}$. The distinct prandial and basal pharmacodynamics of IDegAsp observed in younger adults are preserved in elderly subjects with type 1 diabetes. Drugs Aging. 2015;32:583-90.

20. Morello CM. Pharmacokinetics and pharmacodynamics of insulin analogs in special populations with type 2 diabetes mellitus. Int J Gen Med. 2011;4:827-35.

21. Haahr H, Sasaki T, Bardtrum L, Ikushima I. Insulin degludec/insulin aspart in Japanese patients with type 1 diabetes mellitus: distinct prandial and basal glucose-lowering effects. J Diabetes Investig. 2016;7:574-80.

22. Wangnoo SK, Chowdhury S, Rao PV. Treating to target in type 2 diabetes: the BEGIN trial programme. J Assoc Phys India. 2014;62:21-6.

23. Zinman B, Philis-Tsimikas A, Cariou B, et al. Insulin degludec versus insulin glargine in insulin-naive patients with type 2 diabetes: a 1-year, randomized, treat-to-target trial (BEGIN Once Long). Diabetes Care. 2012;35:2464-71.
24. Heller S, Buse J, Fisher M, et al. Insulin degludec, an ultra-longacting basal insulin, versus insulin glargine in basal-bolus treatment with mealtime insulin aspart in type 1 diabetes (BEGIN Basal-Bolus Type 1): a phase 3, randomised, open-label, treat-to-target non-inferiority trial. Lancet. 2012;379:1489-97.

25. Garber $A J$, King $A B$, Del Prato $S$, et al. Insulin degludec, an ultra-longacting basal insulin, versus insulin glargine in basal-bolus treatment with mealtime insulin aspart in type 2 diabetes (BEGIN Basal-Bolus Type 2): a phase 3, randomised, openlabel, treat-to-target non-inferiority trial. Lancet. 2012;379:1498-507.

26. Mathieu C, Hollander P, Miranda-Palma B, et al. Efficacy and safety of insulin degludec in a flexible dosing regimen vs insulin glargine in patients with type 1 diabetes (BEGIN: Flex T1): a 26-week randomized, treat-to-target trial with a 26-week extension. $\mathrm{J}$ Clin Endocrinol Metab. 2013;98:1154-62.

27. Meneghini L, Atkin SL, Gough SC, et al. The efficacy and safety of insulin degludec given in variable once-daily dosing intervals compared with insulin glargine and insulin degludec dosed at the same time daily: a 26-week, randomized, open-label, parallel-group, treat-to-target trial in individuals with type 2 diabetes. Diabetes Care. 2013;36:858-64.

28. Gough SC, Bhargava A, Jain R, Mersebach H, Rasmussen S, Bergenstal RM. Low-volume insulin degludec 200 units/ml once daily improves glycemic control similarly to insulin glargine with a low risk of hypoglycemia in insulin-naive patients with type 2 diabetes: a 26-week, randomized, controlled, multinational, treat-to-target trial: the BEGIN LOW VOLUME trial. Diabetes Care. 2013;36:2536-42.

29. Onishi Y, Iwamoto Y, Yoo SJ, Clauson P, Tamer SC, Park S. Insulin degludec compared with insulin glargine in insulin-naive patients with type 2 diabetes: a 26-week, randomized, controlled, PanAsian, treat-to-target trial. J Diabetes Investig. 2013;4:605-12.

30. Kumar A, Awata T, Bain SC, et al. Clinical use of the co-formulation of insulin degludec and insulin aspart. Int J Clin Pract. 2016;70:657-67.

31. Fulcher GR, Christiansen JS, Bantwal G, et al. Comparison of insulin degludec/insulin aspart and biphasic insulin aspart 30 in uncontrolled, insulintreated type 2 diabetes: a phase $3 \mathrm{a}$, randomized, treat-to-target trial. Diabetes Care. 2014;37:2084-90.

32. Kaneko S, Chow F, Choi DS, et al. Insulin degludec/ insulin aspart versus biphasic insulin aspart 30 in 
Asian patients with type 2 diabetes inadequately controlled on basal or pre-/self-mixed insulin: a 26-week, randomised, treat-to-target trial. Diabetes Res Clin Pract. 2015;107:139-47.

33. Christiansen JS, Niskanen L, Rasmussen S, Johansen $\mathrm{T}$, Fulcher G. Lower rates of hypoglycemia during maintenance treatment with insulin degludec/insulin aspart versus biphasic insulin aspart 30: a combined analysis of two phase 3 a studies in type 2 diabetes. J Diabetes. 2016;8:720-8.

34. Heise T, Heinemann L, Hövelmann U, Brauns B, Nosek L, Haahr HL, Olsen KJ. Biphasic insulin aspart 30/70: pharmacokinetics and pharmacodynamics compared with once-daily biphasic human insulin and basal-bolus therapy. Diabetes Care. 2009;32:1431-3.

35. Muramatsu N, Akiyama H. Japan: super-aging society preparing for the future. Gerontologist. 2011;51:425-32.

36. World Medical Association. Declaration of Helsinki-ethical principles for medical research involving human subjects. https://www.wma.net/ policies-post/wma-declaration-of-helsinki-ethicalprinciples-for-medical-research-involving-humansubjects/. Accessed Oct 2018.

37. International Council for Harmonisation of Technical Requirements for Pharmaceuticals for Human Use $(\mathrm{ICH})$. Guideline for good clinical practice. https://www.ich.org/fileadmin/Public_Web_Site/ ICH_Products/Guidelines/Efficacy/E6/E6_R1_Guide line.pdf. Accessed Oct 2017.

38. Swinnen SG, Mullins P, Miller M, Hoekstra JB, Holleman F. Changing the glucose cut-off values that define hypoglycaemia has a major effect on reported frequencies of hypoglycaemia. Diabetologia. 2009;52:38-41.

39. International Hypoglycaemia Study Group. Glucose concentrations of less than $3.0 \mathrm{mmol} / \mathrm{L}(54 \mathrm{mg} / \mathrm{dL})$ should be reported in clinical trials: a joint position statement of the American Diabetes Association and the European Association for the Study of Diabetes. Diabetes Care. 2017;40:155-57. 